\title{
Pharmacokinetics and pharmacodynamics of insulin analogs in special populations with type 2 diabetes mellitus
}

This article was published in the following Dove Press journal:

International Journal of General Medicine

9 December 2011

Number of times this article has been viewed

\author{
Candis M Morello ${ }^{1,2}$ \\ 'Skaggs School of Pharmacy and \\ Pharmaceutical Sciences, University \\ of California San Diego, ${ }^{2}$ School \\ of Pharmacy, University of \\ California San Francisco, Veterans \\ Affairs San Diego Healthcare System, \\ San Diego, CA, USA
}

Introduction: The goal of insulin therapy in patients with either type 1 diabetes mellitus (T1DM) or type 2 diabetes mellitus (T2DM) is to match as closely as possible normal physiologic insulin secretion to control fasting and postprandial plasma glucose. Modifications of the insulin molecule have resulted in two long-acting insulin analogs (glargine and detemir) and three rapid-acting insulins (aspart, lispro, and glulisine) with improved pharmacokinetic/ pharmacodynamic (PK/PD) profiles. These agents can be used together in basal-bolus therapy to more closely mimic physiologic insulin secretion patterns.

Methods: This study reviews effects of the multiple demographic and clinical parameters in the insulin analogs glargine, detemir, lispro, aspart, and glulisine in patients with T2DM. A search was conducted on PubMed for each major topic considered (effects of injection site, age, race/ ethnicity, obesity, renal or hepatic dysfunction, pregnancy, exercise, drug interactions) using the topic words and name of each type of insulin analog. Information was also obtained from the prescribing information for each insulin analog.

Results: The PK/PD profiles for insulin analogs may be influenced by many variables including age, weight, and hepatic and renal function. However, these variables do not have equivalent effects on all long-acting or rapid-acting insulin analogs.

Conclusion: Rapid-acting and long-acting insulin analogs represent major advances in treatment for patients with T2DM who require insulin therapy. However, there are potentially important PK and PD differences between the two long-acting agents and among the three rapid-acting insulin analogs, which should be considered when designing treatment regimens for special patient groups.

Keywords: insulin analogs, type 2 diabetes mellitus, pharmacodynamics, pharmacokinetics

\section{Introduction}

Type 2 diabetes mellitus (T2DM) is characterized by a marked and progressive disruption of normal physiologic insulin secretion. There are two key aspects of insulin secretion in healthy individuals: (1) basal insulin secretion by pancreatic $\beta$ cells that occurs continuously to maintain steady glucose levels for extended periods between meals, and (2) prandial secretion in which insulin is rapidly released in an initial first-phase spike in response to a meal, followed by prolonged insulin secretion that returns to basal levels after $2-3$ hours (Figure 1) ${ }^{1-3}$ Insulin is a potent anabolic hormone that binds to insulin receptors to lower blood glucose by facilitating cellular uptake of glucose, amino acids, and fatty acids into skeletal muscle and fat and by inhibiting the output of glucose from the liver. Insulin increases the expression or activity of enzymes that catalyze glycogen, lipid, and protein synthesis, while inhibiting lipolysis 


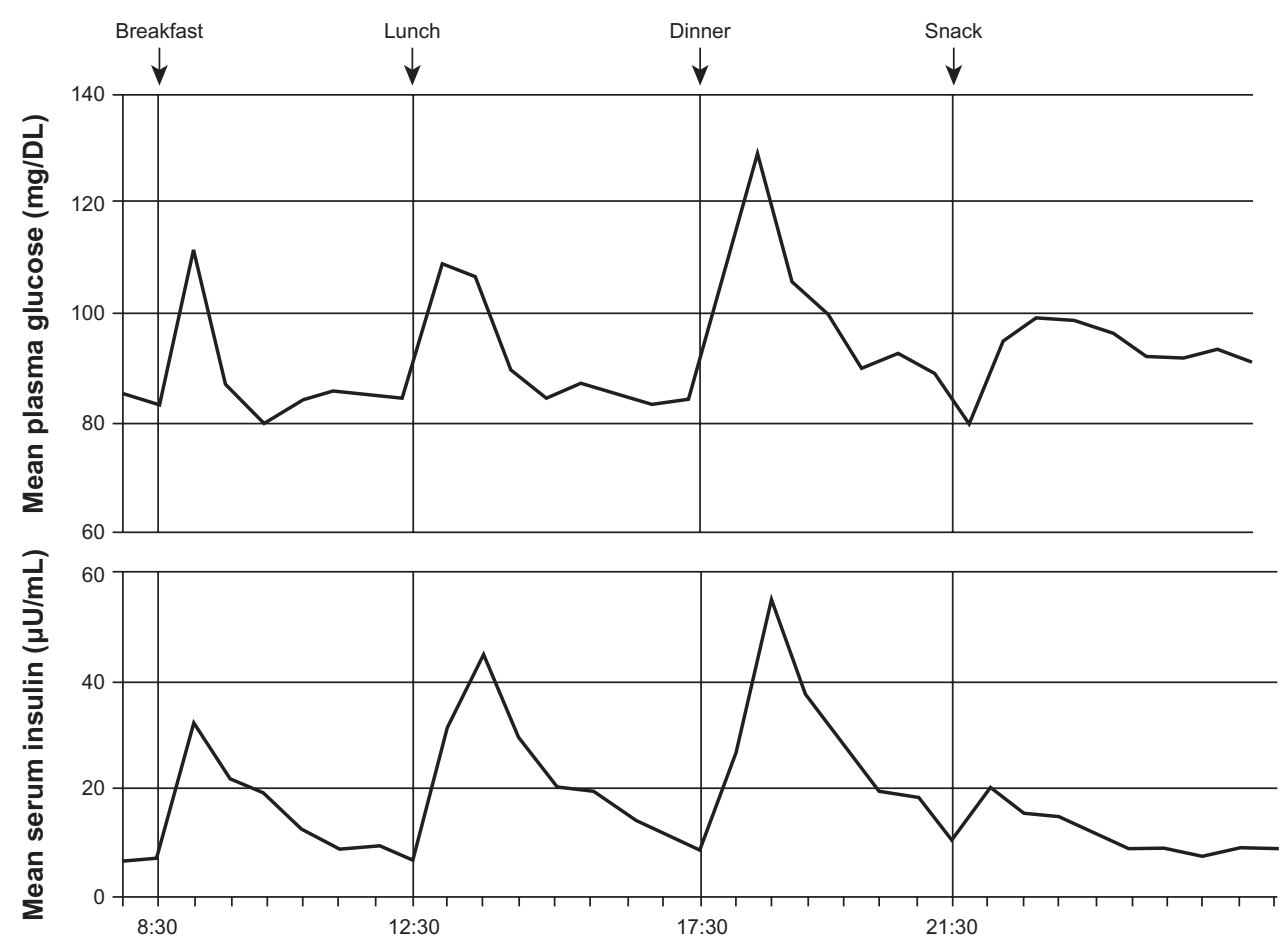

Figure I Mean 24-hour physiologic serum insulin and plasma glucose levels in nondiabetic subjects. ${ }^{3}$

Reprinted from Am J Med, vol. I I3, issue 4, Gerich, Novel insulins: expanding options in diabetes management, pp. 308-316, Copyright (2002), with permission from Elsevier.

and, proteolysis (Figure 2). ${ }^{4,5}$ In normal healthy individuals, physiologic basal and prandial insulin secretions maintain euglycemia, which affects fasting plasma glucose (FPG) and postprandial plasma glucose (PPG) concentrations.

Basal and prandial insulin secretion are impaired in T2DM and early post-meal response is absent. ${ }^{6,7}$ The loss or blunting of this first-phase insulin secretion is important in deterioration of glucose tolerance and elevation of PPG concentrations. ${ }^{7}$ Reduction of basal insulin secretion in patients with T2DM causes unopposed glucagon secretion by pancreatic $\alpha$-cells, which results in increased hepatic glucose output. ${ }^{8,9}$ These effects cause elevations in FPG. Although T2DM is characterized by alterations in insulin secretion, this is only one of many pathologic changes observed in patients. T2DM is also associated with insulin resistance (IR) in peripheral muscle and adipose tissues, which contributes to

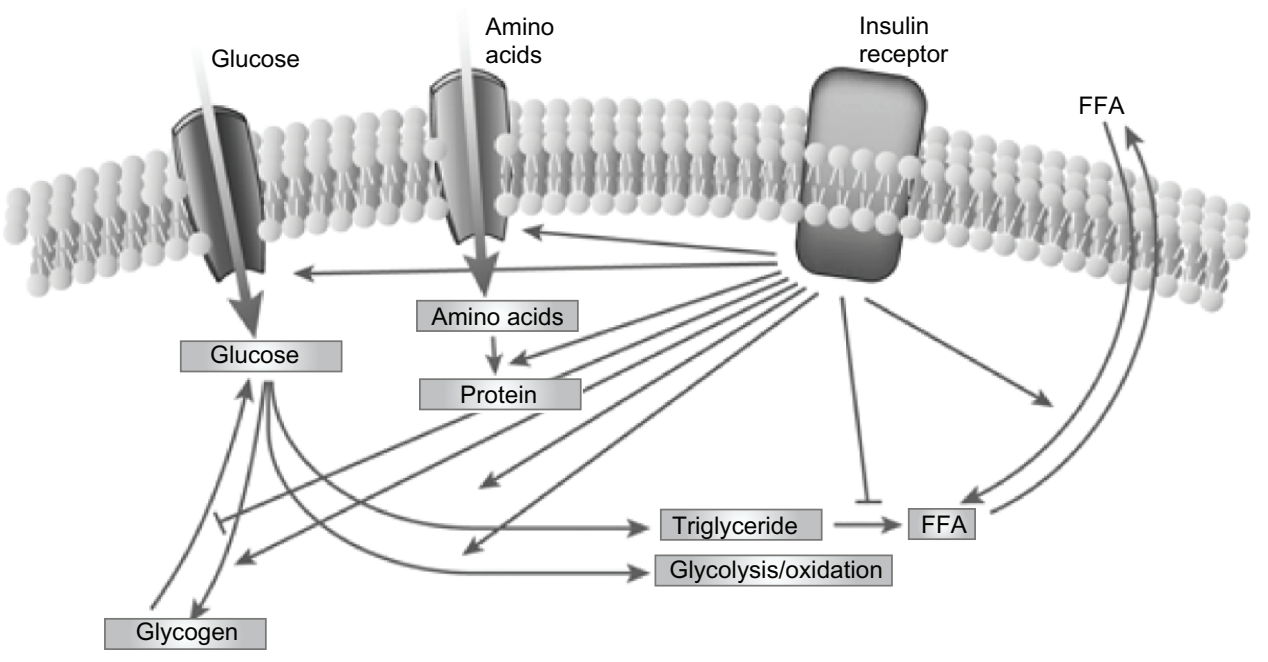

Figure 2 The regulation of metabolism by insulin. ${ }^{5}$

Reprinted from Nature, vol. 4I4, issue 6865, Saltiel and Kahn, Insulin signalling and the regulation of glucose and lipid metabolism, Pp. 799-806, Copyright (200I), with permission from Nature Publishing Group.

Abbreviation: FFA, free fatty acids. 
significantly elevated FPG. ${ }^{7}$ Thus, altered insulin secretion, increased hepatic glucose output, and IR all contribute to loss of glucose control in patients with T2DM.

Treatment of patients with T2DM may include oral and injectable therapies. This paper focuses on insulin therapy for the pharmacotherapeutic treatment of T2DM.

Many patients with T2DM ultimately require insulin therapy to maintain glycemic control. A survey including information from 61,890 patients with T2DM indicated that at $<1,1-5,6-10,11-15,16-20$, and $>20$ years after diagnosis $11 \%, 15 \%, 36 \%, 57 \%, 71 \%$, and $76 \%$ of patients, respectively, were receiving insulin monotherapy or insulin in combination with oral antidiabetes agents. ${ }^{10,11}$ The goal of insulin therapy in type 1 diabetes (T1DM) or T2DM is to match as closely as possible physiologic insulin secretion to control FPG and PPG. ${ }^{9}$ Before the development of insulin analogs, achieving this goal was limited by the characteristics of insulin preparations.

Neutral protamine Hagedorn (NPH) insulin and regular human insulin (RHI) can replace or supplement basal and prandial insulin to control PPG and FPG, but they have important limitations, ${ }^{3,12-14}$ and use of these agents does not result in a good approximation of physiologic insulin secretion. The pharmacokinetic/pharmacodynamic (PK/PD) profile for NPH has a distinct peak; it does not match peakless physiologic basal insulin secretion and requires multiple daily injections (Table 1). ${ }^{12} \mathrm{RHI}$ is administered to control PPG concentrations, but its PK profile is not ideal for achieving this goal. It reaches peak activity relatively slowly ( $>60$ minutes after dosing), ${ }^{13}$ and must be administered at least 30 minutes before meals to control PPG. ${ }^{15}$ Its duration of action is approximately $6-8$ hours and, as a result, plasma insulin levels remain elevated for longer periods after meals, increasing risk for hypoglycemia and insulin stacking with more than twice-daily dosing (Table 1)..$^{3,13,15-17}$ One benefit of the longer action profile of RHI is that it may be used more effectively in patients with gastroparesis and slowed gastric emptying who have delayed carbohydrate absorption. ${ }^{18}$ Overall, however, combination therapy using NPH and RHI does not closely approximate physiologic insulin secretion, may provide limited control over FPG and PPG, and may be associated with high risk for hypoglycemia. ${ }^{3}$

Modifications of the insulin molecule have resulted in two long-acting insulin analogs (glargine and detemir) and three rapid-acting insulin analogs (aspart, lispro, and glulisine) with improved PK/PD profiles (Table 1).,19-24 These agents can be used together in basal-bolus therapy to more closely mimic physiologic insulin secretion patterns. ${ }^{3,15,25}$ Although they may be used together, one difference with insulin analogs compared with human insulin, such as NPH and RHI, is that long-acting analogs may not be mixed in the same syringe with any other insulin preparations and this requires separate injections.

Glargine and high-dose detemir have more predictable flat, time-action, profiles that provide up to 24-hour glucose control and lower risk for hypoglycemia than NPH in patients with T2DM. ${ }^{26-29}$ Equivalent doses of glargine and detemir may provide 24-hour glycemic control in patients with T2DM, although occasionally, higher doses of detemir are required. ${ }^{30,31}$ Rapid-acting insulin analogs have a faster onset and shorter duration of action (DOA) than RHI and provide better control of PPG and may decrease risk for post-meal hypoglycemia. ${ }^{28,32-34}$

The most recent consensus statement from the American Association of Clinical Endocrinologists and the American College of Endocrinology strongly recommends against

Table I Insulin pharmacokinetic profiles ${ }^{a}$

\begin{tabular}{|c|c|c|c|c|c|c|}
\hline Insulin type ${ }^{b}$ & Onset & Peak & DOA & $\begin{array}{l}C_{\max } \\
(\mathrm{mU} / \mathrm{mL})\end{array}$ & $\begin{array}{l}T_{\max } \\
(\min )\end{array}$ & Appearance \\
\hline \multicolumn{7}{|l|}{ Rapid-acting } \\
\hline Lispro' 19 & $5-15$ minutes & $30-60$ minutes & $3-4$ hours & 116 & $30-90$ & Clear, colorless \\
\hline Aspart ${ }^{20}$ & $10-20$ minutes & $40-50$ minutes & $3-5$ hours & 82.1 & $40-50$ & Clear, colorless \\
\hline Glulisine $\mathrm{e}^{21,22}$ & 20 minutes & I hour & 4 hours & 82 & $30-90$ & Clear, colorless \\
\hline \multicolumn{7}{|l|}{ Short-acting } \\
\hline $\operatorname{Regular}^{3,13,15-17}$ & 30 minutes & $60-120$ minutes & $6-8$ hours & 51 & $50-120$ & Clear, colorless \\
\hline \multicolumn{7}{|l|}{ Intermediate-acting } \\
\hline $\mathrm{NPH}^{12}$ & $\mathrm{I}-2$ hours & $3-8$ hours & $12-15$ hours & 22.8 & $360-720$ & Cloudy, white \\
\hline \multicolumn{7}{|l|}{ Long-acting } \\
\hline Glargine ${ }^{c, 23}$ & $\mathrm{I}-2$ hours & Flat $^{\mathrm{c}}$ & $\sim 24$ hours & 18.9 & None & Clear, colorless \\
\hline Detemir $^{\mathrm{d}, 4,24}$ & 1.6 hours & Flat $^{c}$ & Up to 24 hours $^{c}$ & I 49 pmol/L & None & Clear, colorless \\
\hline
\end{tabular}

Notes: a'Estimates only; effects in individual patients vary; ${ }^{b}$ all values are for subcutaneous administration of the insulin analog; 'cannot be mixed with any other insulin requires a separate injection; ${ }^{d}$ varies by dose; higher dose - longer duration.

Abbreviations: DOA, duration of action; NPH, neutral protamine Hagedorn. 
NPH insulin in favor of longer-acting insulin analogs. ${ }^{35}$ This guideline states that use of NPH as a basal insulin has been superseded by the synthetic analogs glargine and detemir, which both provide a relatively peakless profile for approximately 24 hours. Although NPH is less expensive, the analogs offer the opportunity for more physiologic action profiles. The guideline also notes that insulin analogs yield better reproducibility and consistency between and within patients, and a corresponding reduction in risk of hypoglycemia. ${ }^{35}$ Variability in the efficacy and dosing of insulin analogs may occur in certain patient populations, thereby complicating diabetes treatment and increasing the risk of adverse effects. The purpose of this paper is to review the PK/PD characteristics of long- and rapid-acting insulin analogs and their use in special patient populations with T2DM.

\section{Methods}

Several methods were employed in order to identify the most relevant articles to include. A PubMed literature search was conducted to identify peer-reviewed articles published in English from 2000 to 2011. Search terms included "insulin analogs," "insulin lispro," "insulin aspart," "insulin glulisine," "insulin glargine," "insulin detemir," "regular human insulin," "neutral protamine Hagedorn," and "NPH." Each of these terms was individually paired with the following terms: "pharmacokinetics," "pharmacodynamics," "type 2 diabetes," "Caucasian," "African American," "Japanese," "Latino," "Hispanic," "Asian," "obese," "renal," "kidney," "nephropathy," "hepatic," "liver," "pregnant," "gestational diabetes mellitus," "exercise," "physical," and "comorbidity.” The US prescribing information for each insulin was also searched for information related to each topic. Publications that addressed only oral antidiabetes drugs were not included, nor were letters, commentaries, or case studies.

Once the abstracts were reviewed, complete versions of articles that met the criteria noted above were obtained. The contributing authors and the impact factors of the journals in which articles were published were noted, and the study design, methodology, and clinical relevance were assessed. Once publications were identified as relevant, their bibliographies were reviewed and key references were obtained and assessed for inclusion.

The intent of this article is to address the clinical benefits of insulin for specific populations. As a result, a limitation of this analysis is that if an abstract of an article identified during literature searches did not provide information pertaining to such patient groups, the article was not included. Additionally, relevant publications may not have been identified in the PubMed search because they were not indexed in a manner that met the search criteria employed. Another potential limitation to consider is that the identification of relevant publications was performed by the author, and therefore has the potential for subjectivity.

\section{Results}

A total of 118 articles were obtained. After excluding publications that did not meet the pre-identified criteria or failed to provide information relevant to this manuscript, the results and clinical implications provided in 38 references were included.

\section{Factors affecting pharmacokinetic/ pharmacodynamic profiles for insulin analogs}

Several factors may influence the PK/PD of insulin analogs in patients with T2DM. Two of the most important are insulin dose and injection site. The area under the curve (AUC) and DOA for long- and rapid-acting insulin analogs generally increase with dose elevation. ${ }^{24,34,36,37}$ For example, results from a study assessing PK of detemir of $0.15,0.3$, and 0.6 units $/ \mathrm{kg}$ indicated dose-proportional effects on reduction in endogenous glucose production and increased glucose uptake across this dose range. ${ }^{37}$ Results from a second study indicated that the DOA of detemir also increased proportionally with dose and was 5.7, 12.1, 19.9, 22.7, and 23.2 hours for doses of 0.1, 0.2, 0.4, 0.8, and 1.6 units $/ \mathrm{kg}$, respectively. ${ }^{24}$ Glargine doses of $0.5,1.0,1.5$, and 2.0 units $/ \mathrm{kg}$ also produced dose-proportional increases in DOA as reflected by rate of glucose disappearance in a euglycemic clamp study. ${ }^{38}$

The injection site of insulin analogs may also affect their PK/PD profiles. Generally, deeper subcutaneous (SC) injections cause more rapid insulin diffusion and absorption. ${ }^{39}$ High SC fat may slow absorption, altering or delaying the time-action profile. ${ }^{32}$ Severely obese patients may require elevated daily insulin doses and multiple split insulin injections at each dosing interval to improve insulin action and predictability (eg, glargine or detemir 140 units, delivered in two injections of 70 units once daily, with both injection sites separated by 2 inches). Moreover, obese patients with significant central obesity may also require longer needles for effective insulin delivery to prevent leakage of large doses in this dense SC area.

Insulin is most often injected into the SC fat in the abdomen, thigh, or deltoid. Studies exploring long-acting insulin analogs indicate differing effects on PK/PD profiles. 
Results for glargine suggest no clinically significant differences in DOA whether injected into the abdomen, thigh, or deltoid. ${ }^{23}$ For detemir, absolute bioavailability is $64 \%, 59 \%$, and $65 \%$ following SC injection in the abdomen, thigh, and deltoid, respectively. The detemir AUC and maximum plasma concentration $\left(\mathrm{C}_{\max }\right)$ are significantly higher (approximately 10\% and 20\%, respectively) after $\mathrm{SC}$ injection in the abdomen or deltoid, compared with the thigh. ${ }^{40}$ As with any insulin preparations, heat or muscle activity can increase the absorption rate. Abdominal SC tissue provides a predictable absorption rate not as dependent on heat, exercise, or activity compared with muscle and is a preferred site for patients with T2DM. ${ }^{41}$

Studies evaluating rapid-acting insulin analogs suggest that injection site has only a moderate effect on their PK/PD profiles. Results for aspart indicate short time to $\mathrm{C}_{\max }$ and time to maximal concentration $\left(\mathrm{T}_{\max }\right)$ and more rapid onset of PD effect with thigh injection versus deltoid or abdominal injection. ${ }^{42}$ Studies with lispro have shown an earlier $\mathrm{T}_{\text {max }}$ and higher $\mathrm{C}_{\max }$ with abdominal versus deltoid or thigh injection. ${ }^{43}$ The time-concentration profile for glulisine is not significantly influenced by injection site, and bioavailability is $73 \%$ after SC injection into the abdomen, $71 \%$ after injection into the deltoid, and $68 \%$ after injection into the thigh. ${ }^{21}$

Overall, having patients rotate insulin injections within the same location each week (eg, in the abdomen as the preferred site or thigh or deltoid) will decrease variability and improve predictability of insulin response.

\section{Changes in insulin analog PK/PD profiles in special patient populations}

Understanding how PK/PD profiles for specific insulin analogs may be altered in special patient populations may permit proactive dosing adjustments to achieve or maintain glycemic control and decrease the risk of hypoglycemia. Information about the issues addressed in this section is not available for all insulin analogs. For each topic, both published papers and US prescribing information were reviewed.

\section{Elderly patients}

Variability in PK related to declines in renal and/or hepatic function may complicate dosing of insulin and other medications in elderly patients. ${ }^{44}$ Clearance (removal from the bloodstream) of detemir is decreased in the elderly ( $\geq 68$ years of age) and AUC is increased, predisposing them to hypoglycemia. More frequent self-monitoring of blood glucose $(\mathrm{BG})$ is required, especially before operating a vehicle or heavy machinery, and insulin dose adjustments may be needed. ${ }^{4}$ Alterations in PK in elderly patients have not been studied for glargine. Among the rapid-acting insulin analogs, alterations in $\mathrm{PK} / \mathrm{PD}$ have been studied only for aspart. Its PK/PD profile is the same in young and elderly ( $\geq 65$ years old) patients. ${ }^{45}$ Overall, if clearance is reduced and/or AUC increased, the risk for hypoglycemia is elevated, and matching carbohydrate meal content to insulin dose is a necessity to prevent low BG.

\section{Specific racial and ethnic groups}

The PK/PD profile for detemir is consistent in Caucasian, African American, Japanese, and Hispanic groups. ${ }^{4,46}$ Results from a study of 16 African American, 16 Hispanics/ Latinos, and 16 Caucasian patients evaluated with 16-hour isoglycemic glucose clamps and detemir doses of $0.3,0.6$, and 1.2 units/kg indicated linear PK and no differences among racial or ethnic groups. ${ }^{46}$ Results for glargine indicate more rapid absorption in Japanese than Caucasian subjects with T2DM. ${ }^{47}$ PK studies with glargine have not been conducted in other racial or ethnic groups.

Assessment of the effects of race or ethnicity on the PK/PD of rapid-acting insulin analogs has been limited. Results for aspart indicate that its profile in Japanese patients does not differ significantly from that in Caucasians, ${ }^{48}$ and those for glulisine have shown that Japanese subjects have higher initial exposure (33\% higher by AUC over a period of 1 hour) versus Caucasians, ${ }^{21}$ potentially allowing for smaller glulisine doses in Japanese patients with T2DM. The effects of race or ethnicity on the PK/PD of lispro have not been studied.

\section{Obesity}

The prevalence of overweight and obesity among patients with T2DM are both high. The Study to Help Improve Early evaluation and management of risk factors Leading to Diabetes (SHIELD) showed that $28 \%$ of individuals with T2DM are overweight (body mass index [BMI]: $25-29.99 \mathrm{~kg} / \mathrm{m}^{2}$ ) and $59 \%$ are obese $\left(\mathrm{BMI} \geq 30 \mathrm{~kg} / \mathrm{m}^{2}\right) .{ }^{49}$ These associations are consistent for men and women and across racial and ethnic groups. ${ }^{50}$ Obesity and associated SC fat may slow insulin absorption and reduce exposure, altering the PK profile. Obese patients may also require higher starting insulin doses due to obesity-associated IR, ${ }^{51}$ but results suggest that these effects vary across currently available insulin analogs. The effects of obesity on the PK/PD of glargine and detemir have not been studied, but have been assessed for the rapid-acting insulin analogs. It has been reported that there 
is a significant correlation ( $r=0.42,95 \% \mathrm{CI}$ : $0.02-0.82)$ between BMI and time to maximum activity for lispro.

A study in subjects using aspart showed that increasing obesity was significantly correlated with decreased apparent clearance per kg body weight $(P=0.002)$, increased elimination half-life $(P=0.044)$, and elevated AUC $(P=0.006)$. However, it was also noted that these changes were not as great as within-subject variability for these PK parameters. ${ }^{52}$ The prescribing information for aspart also notes that clearance is reduced by $28 \%$ in patients with BMI $>32 \mathrm{~kg} / \mathrm{m}^{2}$ versus those with BMI $<23 \mathrm{~kg} / \mathrm{m}^{2} .{ }^{20}$ Published results have indicated no significant correlation between $\mathrm{BMI}$ and time to maximum activity for glulisine $(r=0.13,95 \% \mathrm{CI}:-0.33-0.59),{ }^{13}$ but the PI for glulisine does state that obesity increases $\mathrm{T}_{\max }$ from 60 minutes to 85 minutes. ${ }^{21}$

\section{Renal dysfunction}

Approximately $20 \%$ of patients with diabetes have renal dysfunction, ${ }^{53}$ and understanding the effects of this common complication on the PK and actions of insulin in these patients is important. Insulin levels are increased in patients with diabetes and overt nephropathy because $30 \%-80 \%$ of circulating insulin is removed by renal excretion. However, the metabolic response to insulin (ie, its effect on PG) is decreased in this population. ${ }^{54}$ It has also been suggested that insulin dosing be decreased in patients with diabetes who have end-stage renal disease, and who are undergoing hemodialysis because they are at increased hypoglycemia risk..$^{55}$ Insulin requirements in these patients may change due to metabolic alterations influencing PK and PD. The prescribing information for detemir indicates no change in PK or PD in patients with renal impairment (RI), although frequent self-monitoring of blood glucose is recommended and dose adjustments may be necessary. ${ }^{4}$

The effects of RI on the PK and actions of glargine have not been studied. ${ }^{23}$ For the rapid-acting insulin analogs, there is an increased PD effect of lispro (ie, elevated glucose-lowering response) as renal function declines, ${ }^{19}$ and renal dysfunction does not alter the PK of aspart. ${ }^{20,52}$ Results for glulisine indicate that subjects with moderate and severe RI have $29 \%$ and $40 \%$ increases in insulin exposure and $20 \%$ and $25 \%$ reductions in clearance, respectively, versus those with normal renal function. ${ }^{21}$ Therefore, glulisine should be empirically reduced in patients with renal insufficiency to prevent hypoglycemia.

\section{Hepatic dysfunction}

The liver plays a central role in maintaining normal glucose concentrations in individuals without diabetes and mediates several processes, including hepatic glucose output and uptake. Changes in hepatic function may also affect the glucose-lowering effects of insulin. ${ }^{56}$ Results for detemir indicate that patients with severe hepatic dysfunction and without diabetes have lower AUC values compared with healthy controls. ${ }^{4}$ The effects of hepatic dysfunction on the PK/PD of glargine have not been studied. ${ }^{23}$ Available information indicates no effects of hepatic impairment on the PK of either lispro or aspart, ${ }^{19,20,52}$ while the effects of liver dysfunction on the PK of glulisine have not been studied. ${ }^{21}$

\section{Pregnancy}

Results from older PK studies indicate that the PK of insulin are not altered during pregnancy. ${ }^{57}$ However, IR is increased during pregnancy, and this may require a higher insulin dose. ${ }^{57,58}$ At present, there is no information about the effects of pregnancy on the PK/PD of any of the insulin analogs.

\section{Exercise}

Any factor that alters blood flow is also likely to alter insulin absorption, with greater blood flow being associated with more rapid insulin absorption. Conditions that modify local blood flow include exercise, massage, bathing in warm water, and the use of vasodilating or vasoconstricting drugs. ${ }^{59}$ However, significant effects of these activities have not been invariably observed with all insulin analogs. Results from a study of 13 patients with T1DM who exercised for 30 minutes, then had radiolabeled glargine injected into the thigh, indicated no increase in the decay of radioactivity versus results obtained after injection without exercise. ${ }^{60}$

Results from a study of eight patients with T1DM who were treated with a standard dose of lispro before a meal of $600 \mathrm{kcal}$ (75 g carbohydrate) and who, 90 minutes later, undertook postprandial exercise at $25 \%$ maximum oxygen consumption $\left(\mathrm{VO}_{2 \max }\right)$ for 60 minutes, $50 \% \mathrm{VO}_{2 \max }$ for 30 and 60 minutes, and $75 \% \mathrm{VO}_{2 \text { max }}$ for 30 minutes, indicated increased risk for hypoglycemia at all exercise intensities. ${ }^{61}$ A reduced lispro dose or a pre-exercise snack should be considered before exercise to prevent low-BG events. It is reasonable to suggest that this recommendation should also be applied for patients taking other rapid-acting insulin analogs.

\section{Drug interactions with insulin analogs}

Patients with T2DM are likely to have comorbid conditions (eg, hypertension, dyslipidemia), which require chronic pharmacologic treatment. ${ }^{62}$ Insulin treatment in these patients requires attention to drug interactions that may 
Table 2 Variables and potential effects on insulin analog dosing

\begin{tabular}{|c|c|c|}
\hline Variable & Potential effect & Action needed* \\
\hline Insulin dose $\mathrm{e}^{24,37,38}$ & Duration of action increases with increasing doses & $\begin{array}{l}\text { Dose adjustments should be more conservative } \\
\text { as the administered dose increases }\end{array}$ \\
\hline Injection site $21,23,29,32,40-43$ & $\begin{array}{l}\text { Absorption varies with site of injection, heat, } \\
\text { muscle activity; abdomen has least variability }\end{array}$ & $\begin{array}{l}\text { Rotate injection sites within the same body region } \\
\text { to decrease variability and improve predictability } \\
\text { of response }\end{array}$ \\
\hline Older age $\mathrm{e}^{4,44,45}$ & $\begin{array}{l}\text { Increased insulin effects with possible decreased } \\
\text { clearance and increased AUC }\end{array}$ & $\begin{array}{l}\text { Match carbohydrate meal content to insulin dose } \\
\text { for rapid-acting insulins; initial dose and dose } \\
\text { adjustments should be conservative }\end{array}$ \\
\hline Racial and ethnic groups ${ }^{4,21,46-48}$ & $\begin{array}{l}\text { No difference in absorption for detemir or aspart; } \\
\text { more rapid absorption for glargine and higher initial } \\
\text { exposure for glulisine in Japanese patients }\end{array}$ & $\begin{array}{l}\text { Data are limited; no adjustment needed for detemir } \\
\text { or aspart; adjustments may be needed for Japanese } \\
\text { patients receiving glargine or glulisine }\end{array}$ \\
\hline Obesity ${ }^{\mid 3,20,21,49-51}$ & $\begin{array}{l}\text { Slower absorption and reduced exposure of insulin } \\
\text { analogs with increased subcutaneous fat; decreased } \\
\text { clearance may occur with some insulin analogs }\end{array}$ & $\begin{array}{l}\text { Higher starting doses may be required because } \\
\text { of insulin resistance, but not consistent across } \\
\text { insulin analogs }\end{array}$ \\
\hline Renal dysfunction ${ }^{4,19-21,23,52-55}$ & $\begin{array}{l}\text { Insulin clearance decreased, insulin levels increase, } \\
\text { metabolic responses to insulin decrease }\end{array}$ & $\begin{array}{l}\text { Dose requirements may decrease for patients } \\
\text { with moderate to severe renal dysfunction }\end{array}$ \\
\hline Hepatic dysfunction ${ }^{4,19-21,23,52,56}$ & $\begin{array}{l}\text { Data are limited; hepatic clearance of insulin } \\
\text { decreased }\end{array}$ & $\begin{array}{l}\text { Dose requirements may decrease in severe hepatic } \\
\text { dysfunction and be unchanged in mild to moderate } \\
\text { dysfunction }\end{array}$ \\
\hline Pregnancy ${ }^{57,58}$ & $\begin{array}{l}\text { No data available for insulin analogs; } \\
\text { insulin resistance increased }\end{array}$ & Dose requirements may increase \\
\hline Exercise ${ }^{59-61}$ & Increased absorption possible from muscle sites & $\begin{array}{l}\text { May need to reduce doses of rapid-acting } \\
\text { analogs before exercise }\end{array}$ \\
\hline
\end{tabular}

Note: *Frequent self-monitoring of blood glucose is recommended for patients with any of these variables (which could potentially affect insulin analog dosing) until the patient is on a stable dose of the insulin analog.

Abbreviation: AUC, area under the curve.

alter insulin PK/PD. Information about interactions between insulin and other medications is scarce; specific drug interactions are not listed in the PIs for the insulin analogs. This advice has been provided, however: drugs that potentially increase the BG-lowering effect of insulins and susceptibility to hypoglycemia include oral antidiabetic products, pramlintide, angiotensin-converting enzyme inhibitors, disopyramide, fibrates, fluoxetine, monoamine oxidase inhibitors, propoxyphene, pentoxifylline, salicylates, somatostatin analogs, and sulfonamide antibiotics. Drugs that potentially reduce the BG-lowering effect of insulins include corticosteroids, niacin, danazol, diuretics, sympathomimetic agents (eg, epinephrine, albuterol, terbutaline), glucagon, isoniazid, phenothiazine derivatives, somatropin, thyroid hormones, estrogens, progestogens (eg, in oral contraceptives), protease inhibitors, and atypical antipsychotic medications (eg, olanzapine and clozapine). Increased self-monitoring of $\mathrm{BG}$ and closer follow-up are required in patients taking these medications, and insulin doses should be adjusted based on pattern management of 1-2 weeks of patient glucose logbook records. ${ }^{19-21,23}$

\section{Conclusion}

Many patients with T2DM will require insulin therapy to maintain glycemic control. Management of these patients has been facilitated by development of rapid-acting and long-acting insulin analogs, which can be combined to more closely mimic physiologic insulin secretion. PK/PD for insulin analogs may be influenced by age, weight, ethnicity or race, pregnancy, activity level, and hepatic and renal function (Table 2). 4,13,19-21,23,24,29,32,37,38,40-61 However, these variables do not have equivalent effects on all rapid-acting or long-acting insulin analogs. While some effects on PK/PD of insulin analogs may seem subtle, they may account for the difficulties encountered by providers when establishing glycemic control. Patients with characteristics potentially affecting insulin $\mathrm{PK} / \mathrm{PD}$ may require dosing alterations and closer monitoring than others with T2DM receiving insulin therapy. Because all these factors may affect PK/PD parameters, individualized monitoring is imperative to reach glucose goals effectively and safely and decrease the risks of long-term hyperglycemia.

\section{Acknowledgments}

The author would like to thank Robert W Rhoades, PhD of MedVal Scientific Information Services, LLC, for providing medical writing and editorial assistance. The author verifies that she meets all International Committee of Medical Journal Editors (ICMJE) requirements for authorship. This manuscript was prepared according to the 
International Society for Medical Publication Professionals' Good Publication Practice for Communicating CompanySponsored Medical Research: The GPP2 Guidelines. Funding to support the preparation of this manuscript was provided by Novo Nordisk Inc.

\section{Disclosure}

The author reports no conflicts of interest in this work. The author did not receive an honorarium for this work.

\section{References}

1. Bogardus C, Tataranni PA. Reduced early insulin secretion in the etiology of type 2 diabetes mellitus in Pima Indians. Diabetes. 2002; 51(Suppl 1): S262-S264.

2. King AB, Armstrong DU. Basal bolus dosing: a clinical experience. Curr Diabetes Rev. 2005;1:215-220.

3. Gerich JE. Novel insulins: expanding options in diabetes management. Am J Med. 2002;113:308-316.

4. Levemir ${ }^{\circledR}$ (insulin detemir [rDNA origin] injection) [prescribing information]. Princeton, NJ: Novo Nordisk Inc; 2010.

5. Saltiel AR, Kahn CR. Insulin signalling and the regulation of glucose and lipid metabolism. Nature. 2001;414:799-806.

6. Kahn SE, Montgomery B, Howell W, et al. Importance of early phase insulin secretion to intravenous glucose tolerance in subjects with type 2 diabetes mellitus. J Clin Endocrinol Metab. 2001;86: 5824-5829.

7. Guillausseau PJ, Meas T, Virally M, Laloi-Michelin M, Medeau V, Kevorkian JP. Abnormalities in insulin secretion in type 2 diabetes mellitus. Diabetes Metab. 2008;34(Suppl 2):S43-S48.

8. Burcelin R, Knauf C, Cani PD. Pancreatic alpha-cell dysfunction in diabetes. Diabetes Metabolism. 2008;34(Suppl 2):S49-S55.

9. Campbell RK, White JR Jr. Insulin therapy in type 2 diabetes. $J$ Am Pharm Assoc (Wash). 2002;42:602-611.

10. Eliasson B, Eeg-Olofsson K, Cederholm J, Nilsson PM, Gudbjornsdottir S. Antihyperglycaemic treatment of type 2 diabetes: results from a national diabetes register. Diabetes Metab. 2007;33:269-276.

11. Owens DR. Insulin preparations with prolonged effect. Diabetes Technol Ther. 2011;13(Suppl 1):S5-S14.

12. Schmid H. New options in insulin therapy. J Pediatria (Rio J). 2007; 83(Suppl 5):S146-S155.

13. Becker RHA, Frick AD, Burger F, Potgieter JH, Scholtz H. Insulin glulisine, a new rapid-acting insulin analogue, displays a rapid timeaction profile in obese non-diabetic subjects. Exp Clin Endocrinol Diabetes. 2005;113:435-443.

14. Osterberg O, Erichsen L, Ingwersen SH, Plum A, Poulsen HE, Vicini P. Pharmacokinetic and pharmacodynamic properties of insulin aspart and human insulin. J Pharmacokinet Pharmacodyn. 2003;30:221-235.

15. Levy P. Insulin analogs or premixed insulin analogs in combination with oral agents for treatment of type 2 diabetes. Med Gen Med. 2007;9:12.

16. Novolin ${ }^{\circledR}$ R [prescribing information]. Princeton, NJ: Novo Nordisk Inc; May 14, 2010.

17. Novolin ${ }^{\circledR} \mathrm{N}$ [prescribing information]. Princeton, NJ: Novo Nordisk Inc; May 14, 2010.

18. Walsh JA, Roberts R, Bailey T, Varma CB. Using Insulin: Everything You Need for Success With Insulin. San Diego, CA: Torrey Pines Press; 2003.

19. Humalog ${ }^{\circledR}$ (insulin lispro [rDNA origin] injection) [prescribing information]. Indianapolis, IN: Eli Lilly and Company; May 18, 2011.

20. $\operatorname{NovoLog}^{\circledR}$ (insulin aspart [rDNA origin] injection) [prescribing information]. Princeton, NJ: Novo Nordisk Inc; July, 2011.

21. Apidra ${ }^{\circledR}$ (insulin glulisine) [prescribing information]. Bridgewater, $\mathrm{NJ}$ : Sanofi-Aventis; 2009.
22. Helms KL, Kelley KW. Insulin glulisine: an evaluation of its pharmacodynamic properties and clinical application. Ann Pharmacother. 2009;43:658-668.

23. Lantus ${ }^{\circledR}$ (insulin glargine [rDNA origin] injection) [prescribing information]. Bridgewater, NJ: Sanofi-Aventis; March 2, 2007.

24. Plank J, Bodenlenz M, Sinner F, et al. A double-blind, randomized, dose-response study investigating the pharmacodynamic and pharmacokinetic properties of the long-acting insulin analog detemir. Diabetes Care. 2005;28:1107-1112.

25. Raccah D, Bretzel RG, Owens D, Riddle M. When basal insulin therapy in type 2 diabetes mellitus is not enough - what next? Diabetes Metab Res Rev. 2007;23:257-264.

26. Garber AJ, Clauson P, Pedersen CB, Kolendorf K. Lower risk of hypoglycemia with insulin detemir than with neutral protamine hagedorn insulin in older persons with type 2 diabetes: a pooled analysis of phase III trials. J Am Geriatr Soc. 2007;55:1735-1740.

27. Riddle MC, Rosenstock J, Gerich J. The Treat-to-Target trial: randomized addition of glargine or human NPH insulin to oral therapy of type 2 diabetic patients. Diabetes Care. 2003;26:3080-3086.

28. Hermansen K, Fontaine P, Kukolja KK, Peterkova V, Leth G, Gall MA. Insulin analogues (insulin detemir and insulin aspart) versus traditional human insulins (NPH insulin and regular human insulin) in basal-bolus therapy for patients with type 1 diabetes. Diabetologia. 2004;47: 622-629.

29. Hompesch M, Ocheltree SM, Wondmagegnehu ET, et al. Pharmacokinetics and pharmacodynamics of insulin lispro protamine suspension compared with insulin glargine and insulin detemir in type 2 diabetes. Curr Med Res Opin. 2009;25:2679-2687.

30. King AB. Once-daily insulin detemir is comparable to once-daily insulin glargine in providing glycaemic control over $24 \mathrm{~h}$ in patients with type 2 diabetes: a double-blind, randomized, crossover study. Diabetes Obes Metab. 2009;11:69-71.

31. Pscherer S, Dietrich ES, Dippel FW, Neilson AR. Comparison of one-year costs of type 2 diabetes treatment with insulin glargine or insulin detemir in a basal supported oral therapy (BOT) in Germany. Int J Clin Pharmacol Ther. 2010;48:129-137.

32. Barnett $\mathrm{AH}$. How well do rapid-acting insulins work in obese individuals? Diabetes Obes Metab. 2006;8:388-395.

33. Roach P. New insulin analogues and routes of delivery: pharmacodynamic and clinical considerations. Clin Pharmacokinet. 2008;47: 595-610.

34. Becker RH, Frick AD. Clinical pharmacokinetics and pharmacodynamics of insulin glulisine. Clin Pharmacokinet. 2008;47:7-20.

35. Rodbard HW, Jellinger PS, Davidson JA, et al. Statement by an American Association of Clinical Endocrinologists/American College of Endocrinology consensus panel on type 2 diabetes mellitus: an algorithm for glycemic control. Endocr Pract. 2009;15:540-559.

36. Lindholm A, Jacobsen LV. Clinical pharmacokinetics and pharmacodynamics of insulin aspart. Clin Pharmacokinet. 2001;40:641-659.

37. Wutte A, Plank J, Bodenlenz M, et al. Proportional dose-response relationship and lower within-patient variability of insulin detemir and NPH insulin in subjects with type 1 diabetes mellitus. Exp Clin Endocrinol Diabetes. 2007;115:461-467.

38. Wang Z, Hedrington MS, Gogitidze JN, et al. Dose response effects of insulin glargine in type 2 diabetes. Diabetes Care. 2010;33:1555-1560.

39. Gin H, Hanaire-Broutin H. Reproducibility and variability in the action of injected insulin. Diabetes Metab. 2005;31:7-13.

40. EMEA. Scientific discussion of insulin detemir. 2004. Available at: http://www.ema.europa.eu/docs/en_GB/document_library/EPAR_-Scientific_Discussion/human/000528/WC500036658.pdf. Accessed November 16, 2011.

41. Injection site selection. Available at: http://www.bd.com/us/diabetes/ page.aspx?cat=7001\&id=7261. Accessed November 10, 2011.

42. Mudaliar SR, Lindberg FA, Joyce M, et al. Insulin aspart (B28 aspinsulin): a fast-acting analog of human insulin: absorption kinetics and action profile compared with regular human insulin in healthy nondiabetic subjects. Diabetes Care. 1999;22:1501-1506. 
43. ter Braak EW, Woodworth JR, Bianchi R, et al. Injection site effects on the pharmacokinetics and glucodynamics of insulin lispro and regular insulin. Diabetes Care. 1996;19:1437-1440.

44. Corsonello A, Pedone C, Incalzi RA. Age-related pharmacokinetic and pharmacodynamic changes and related risk of adverse drug reactions. Curr Med Chem. 2010;17:571-584.

45. Krones R, Schutte C, Heise T. The rapid-acting properties of insulin aspart are preserved in elderly people with type 2 diabetes. Diabetes Obes Metab. 2009;11:41-44.

46. Hompesch M, Troupin B, Heise T, et al. Time-action profile of insulin detemir and NPH insulin in patients with type 2 diabetes from different ethnic groups. Diabetes Obes Metab. 2006;8:568-573.

47. Rave K, Nosek L, Heinemann L, Frick A, Becker R. Time-action profile of the long-acting insulin analogue insulin glargine in comparison to NPH insulin in Japanese volunteers. Diabetes Metab. 2003;29: $430-431$.

48. Kaku K, Matsuda M, Urae A, Irie S. Pharmacokinetics and pharmacodynamics of insulin aspart, a rapid-acting analog of human insulin, in healthy Japanese volunteers. Diabetes Res Clin Pract. 2000;49:119-126.

49. Bays HE, Chapman RH, Grandy S. The relationship of body mass index to diabetes mellitus, hypertension and dyslipidaemia: comparison of data from two national surveys. Int J Clin Pract. 2007;61:737-747.

50. Crawford AG, Cote C, Couto J, et al. Prevalence of obesity, type II diabetes mellitus, hyperlipidemia, and hypertension in the United States: findings from the GE centricity electronic medical record database. Popul Health Manag. 2010;13:151-161.

51. Fernandez-Veledo S, Nieto-Vazquez I, Vila-Bedmar R, Garcia-Guerra L, Alonso-Chamorro M, Lorenzo M. Molecular mechanisms involved in obesity-associated insulin resistance: therapeutical approach. Arch Physiol Biochem. 2009;115:227-239.

52. Holmes G, Galitz L, Hu P, Lyness W. Pharmacokinetics of insulin aspart in obesity, renal impairment, or hepatic impairment. Br J Clin Pharmacol. 2005;60:469-476.
53. Craig KJ, Donovan K, Munnery M, Owens DR, Williams JD, Phillips AO. Identification and management of diabetic nephropathy in the diabetes clinic. Diabetes Care. 2003;26:1806-1811.

54. Rave K, Heise T, Pfutzner A, Heinemann L, Sawicki PT. Impact of diabetic nephropathy on pharmacodynamic and pharmacokinetic properties of insulin in type 1 diabetic patients. Diabetes Care. 2001;24: 886-890.

55. Shrishrimal K, Hart P, Michota F. Managing diabetes in hemodialysis patients: observations and recommendations. Cleve Clin J Med. 2009; 76:649-655.

56. Home PD, Pacini G. Hepatic dysfunction and insulin insensitivity in type 2 diabetes mellitus: a critical target for insulin-sensitizing agents. Diabetes Obes Metab. 2008;10:699-718.

57. Gray RS, Cowan P, Steel JM, Johnstone FD, Clarke BF, Duncan LJ. Insulin action and pharmacokinetics in insulin treated diabetics during the third trimester of pregnancy. Diabetes Metab. 1984;1:273-278.

58. Klieger C, Pollex E, Kazmin A, Koren G. Hypoglycemics: pharmacokinetic considerations during pregnancy. Ther Drug Monit. 2009;31:533-541.

59. Guerci B, Sauvanet JP. Subcutaneous insulin: pharmacokinetic variability and glycemic variability. Diabetes Metab. 2005;31:4S7-4S24.

60. Peter R, Luzio SD, Dunseath G, et al. Effects of exercise on the absorption of insulin glargine in patients with type 1 diabetes. Diabetes Care. 2005;28:560-565.

61. Rabasa-Lhoret R, Bourque J, Ducros F, Chiasson JL. Guidelines for premeal insulin dose reduction for postprandial exercise of different intensities and durations in type 1 diabetic subjects treated intensively with a basal-bolus insulin regimen (ultralente-lispro). Diabetes Care. 2001;24:625-630.

62. EDIC Research Group. Epidemiology of Diabetes Interventions and Complications (EDIC): design, implementation, and preliminary results of a long-term follow-up of the diabetes control and complications trial cohort. Diabetes Care. 1999;22:99-111.
International Journal of General Medicine

\section{Publish your work in this journal}

The International Journal of General Medicine is an international, peer-reviewed open-access journal that focuses on general and internal medicine, pathogenesis, epidemiology, diagnosis, monitoring and treatment protocols. The journal is characterized by the rapid reporting of reviews, original research and clinical studies across all disease areas.

\section{Dovepress}

A key focus is the elucidation of disease processes and management protocols resulting in improved outcomes for the patient.The manuscript management system is completely online and includes a very quick and fair peer-review system. Visit http://www.dovepress.com/ testimonials.php to read real quotes from published authors. 